\title{
Blatant, Subtle and Insidious: URM Faculty Perceptions of Discriminatory Practices in Predominantly White Institutions
}

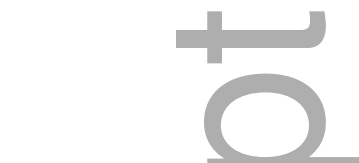 \\ Direct Correspondence to: \\ Ruth Enid Zambrana, PhD \\ University of Maryland, College Park \\ Professor, Department of Women's Studies \\ 1208 Cole Student Activities Building \\ College Park, MD 20742 \\ E-mail: rzambran@umd.edu

\section{Adia Harvey Wingfield, PhD} \\ Washington University in St. Louis \\ Professor, Department of Sociology \\ Seigle Hall 207 Box 1112 \\ Washington University in St. Louis \\ 1 Brookings Drive \\ St. Louis MO 63130 \\ ahwingfield@wustl.edu
}

Director, Consortium on Race, Gender and Ethnicity

\section{Lisa M. Lapeyrouse, PhD}

University of Michigan Flint

Assistant Professor, Public Health \& Health Sciences

1lapeyro@umflint.edu

\section{Brianne A. Dávila, PhD}

This is the author manuscript accepted for publication and has undergone full peer review but has not been through the copyediting, typesetting, pagination and proofreading process, which may lead to differences between this version and the Version of Record. Please cite this article as doi: $\underline{10.1111 / \text { soin. } 12147}$

This article is protected by copyright. All rights reserved 
California State Polytechnic University, Pomona

Assistant Professor, Psychology and Sociology Department

3801 West Temple Ave.

Pomona, CA 91768

(909) 979-5531

badavila@cpp.edu

Tangere L. Hoagland

University of Maryland, College Park

Doctoral Student, Department of Women's Studies

2101 Woods Hall

College Park, MD 20742

thoagland3@gmail.com

\section{R. Burciaga Valdez, PhD}

University of New Mexico

Robert Wood Johnson Foundationon Professor, Family \& Community Medicine and Economics

RWJF Center for Health Policy at the University of New Mexico

1909 Las Lomas, MSC02 1645

1 University of New Mexico

Albuquerque, NM 87131-0001

rovaldez@aol.com

FUNDING

Funding for this research was initially provided by the Robert Wood Johnson Foundation (RWJF), Grant \#68480, the University of Maryland Tier 1 Seed Grants, Division of Research, Faculty Incentive Program, and is currently supported by the Annie E. Casey Foundation (AECF) (\#214.0277). 


\section{ACKNOWLEDGMENTS}

An earlier version of this paper was presented at the Eastern Sociological Society in Baltimore, MD on February 21, 2014. We wish to thank Dr. Laura A. Logie for project management, and Ms. Wendy Hall for manuscript preparation. We are especially grateful to Dr. Debra J. Pérez, Vice President for Research and Evaluation at AECF for her support, guidance, and enthusiasm about this study. Finally, and most importantly, we want to thank the URM faculty across the U.S. who participated in the study.

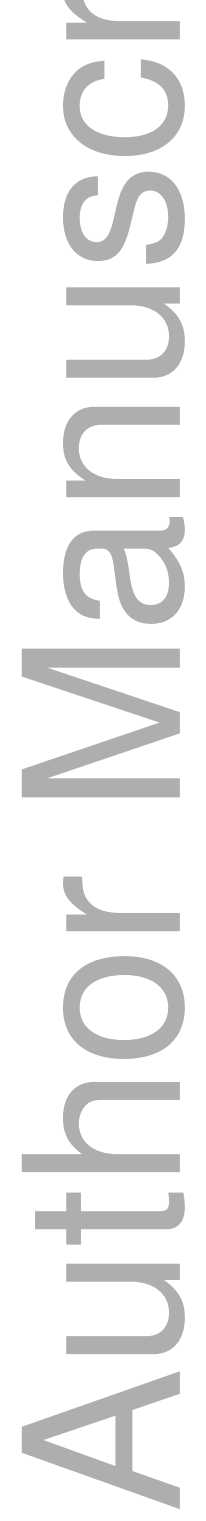


Received Date : 12-Nov-2015

Revised Date : 17-Aug-2016

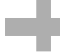

Accepted Date : 01-Sep-2016

Article type : Special Issue

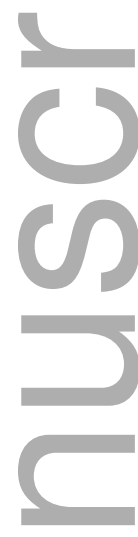

Blatant, Subtle and Insidious: URM Faculty Perceptions of

Discriminatory Practices in Predominantly White Institutions

Abstract

Although modest gains are observed in the number of African American, Mexican American, and Puerto Rican faculty in higher education institutions, systemic issues of underrepresentation and retention remain problematic. This paper describes how Historically Underrepresented Minority (URM) faculty in Predominantly White Institutions perceive discrimination and illustrates the ways in which discriminatory institutional practices - such as microaggressions - manifest and contribute to unwelcoming institutional climates and workplace stress. Using a mixed methods approach, including survey data and individual and group interviews, findings show that respondents $(n=543)$ encounter racial discrimination from colleagues and administrators; experience discrimination differently based on their race/ethnicity and gender; and report difficulties in describing racist encounters. Qualitative data reveal three themes that inform the survey results on perceived discrimination: 1) blatant, outright, subtle, and insidious racism; 2) devaluation of scholarly contributions, merit, and skillset by colleagues and administrators; and 3) the burden of "representing minorities," or a "racial/ethnic tax." Propositions for how to change unwelcoming environments and create safe spaces for professional development to reduce the adverse effects of discrimination among URM faculty are discussed.

Abstract words: 175

Blatant, Subtle and Insidious: URM Faculty Perceptions of

This article is protected by copyright. All rights reserved 


\section{Discriminatory Practices in Predominantly White Institutions}

\section{Introduction}

Within academia the intertwined effects of racism, sexism, and classism contribute to an unwelcoming and often hostile work environment for historically underrepresented minority (URM) faculty, particularly within the context of the so-called, "post-racial era" (Turner, Gonzalez, and Wood 2008; Bonilla-Silva 2009). As universities pursue diversity hiring initiatives to mitigate the White, patriarchal hegemony of academia, studies report the limited extent to which higher education institutions have gone beyond mere "talk" to reach critical levels of diversity (Henderson and Herring 2013; Gutierrez y Muhs et al. 2012). Few studies have explored how the intersecting identities of race/ethnicity, gender, and class among URM faculty influence perceptions of discrimination in workplace interactions and its potential impact on retention. A more profound inquiry investigating how perceived discrimination and institutional racism impact career success among URM faculty remains under-examined (Agathangelou and Ling 2002; Bell, Morrow, and Tastsoglou 1999). The omission of intersecting identities in research on discrimination represents an important knowledge limitation (HillCollins 2015; Ridgeway 2014). The focus on one single attribute such as race/ethnicity fails to acknowledge that "individuals frequently occupy more than one socially (dis)advantaged status and that these statuses may interact to shape their experiences" (Lewis, Cogburn and Williams 2015, p.419). Neglecting to acknowledge the impact of intersecting identities in higher education masks racism and discrimination behind what appears to be, and is promoted as, impersonal and fair standard operating procedures or embedded social and organizational norms.

Our study sample includes African American, Mexican American, and Puerto Rican faculty, groups that are underrepresented in academia relative to their proportion of the U.S. population. Modest gains have been made over the past few decades in terms of numbers. For example, the percentage of African American faculty increased from 3.2 percent in 1988 to 5.0 percent in 2010, and the percentage of Hispanic faculty increased from 2.4 percent to 3.6 percent during the same period. The percentage of Black and Hispanic faculty who earned tenure and promotion to full professorship, however, has remained relatively stagnant during the last three decades (U.S. Department of Education 2011). In fall 2013, these groups in total represented about 11 percent of faculty (U.S. Department of Education 2015), yet together constitute over one-third of the U.S. population.

This article is protected by copyright. All rights reserved 
This paper describes the perceptions of discriminatory incidents by URM faculty respondents that contribute to unwelcoming climates and workplace stress experienced by underrepresented minority faculty in predominantly White institutions (PWI). Two major questions guide this inquiry: 1 ) What types (racial/ethnic, gender, or class) of discrimination are most likely to be encountered? and 2) Do perceptions of discrimination differ based on racial/ethnic, gender or class identity? Specifically, we explore the ways in which URM faculty perceive institutional racism in PWI.

\section{The White Racial Frame and the Crisis of Legitimacy: Microaggressions in the Ivory Tower}

We use the concept of White racial framing to contextualize the microaggressions URM faculty encounter in university settings. White racial framing is defined as a set of beliefs, stereotypes, sincere fictions, and emotionally driven actions that collectively reinforce a racial hierarchy of White dominance and superiority over non-Whites. An individual may espouse this body of beliefs (consciously or unconsciously), or it can characterize institutional practices. In the latter case, when this framing is embedded in an institution, then aspects of organizational culture, routinized interactions, and/or discrimination can maintain racial/ethnic inequities (Feagin 2006). For example, in a study of elite law schools, Moore (2008) illustrates how White racial framing shapes perceptions of URM students as unfit for the legal field, constructs curriculum that centralizes Whiteness, and compels URM law students to engage in emotion management to address feelings of frustration in response to racial issues. These underlying beliefs, attitudes and stereotypes promote institutional racism that can permeate the way an institution functions; "allow Whites to collude in or rationalize the systemic processes that facilitate and maintain ongoing racial privilege and inequality... [and] obscure attention to the existence and consequences of these deep structural inequalities" (Wingfield and Feagin 2012: 144).

We argue that these institutionalized processes establish a context for the microaggressions that URM faculty encounter, and facilitate the crisis of legitimacy (Feagin 2013; Moore 2008; Turner, Gonzales and Wood 2008). Accordingly, the crisis of legitimacy is based on three unfounded, implicit assumptions and perceptions regarding URM faculty: 1) their scholarship is "biased" (Stanley 2007); 2) they are undeserving benefactors of affirmative action (Turner and Myers 2000); and 3) they do not "look" or "act" the part of a professional (Harlow 2003). These challenges are embedded in daily work stress that includes negative racial images and stereotypes that denigrate URM faculty, while simultaneously exalting their White counterparts. Often, White individuals pretend not to notice differences and/or minimize racism in an attempt to explain that "color" was not involved in actions taken (Sue et al. 2007; Bonilla-Silva 2009:.29). This belief in color-blindness is deeply entrenched in organizational practices that deny equal access and opportunities (Wingfield and Alston 2014). To the

This article is protected by copyright. All rights reserved 
point, non-URM faculty is conditioned and rewarded for remaining unaware of how their beliefs and actions may unfairly oppress people (Sue 2004), and the resultant institutional climate ultimately denies URM faculty their earned status as legitimate professionals and an equal opportunity to achieve career success.

\section{Inhospitable Environments: Fostering Daily Microaggressions}

Unspoken values and beliefs produce inhospitable environments and foster daily microaggressions that affect URM faculty, especially in research-extensive universities. Scholars acknowledge the presence of racism and have developed taxonomies to address its more subtle forms, which range from microaggressions to acute and chronic discrimination. Sue et al. (2007) conceptualize stressors in terms of racial microaggressions, which are defined as "brief and commonplace daily verbal, behavioral, and environmental indignities, whether intentional or unintentional, that communicate hostile, derogatory, or negative racial slights and insults to the target person or group" (273). Other scholars categorize discrimination in terms of acute and chronic racial discrimination (Harnois and Ifatunji 2011; Pager and Shepherd 2008; Sewell 2015; Williams and Mohammed 2009). Acute racial discrimination is responsible for a wide variety of incidents including being denied promotion, being denied employment, or being discouraged by a teacher. Chronic racial discrimination or daily microaggressions play a role in the frequency with which everyday discrimination is experienced. This includes being treated with less respect, and living in an environment of fear, insults, threats, or harassment. Further, discrimination can make an individual feel unintelligent, dishonest, or inferior.

Essien (2003), described how racial/ethnic minority law school faculty professors experienced both visible and invisible barriers which crippled their chances of succeeding in academia. Visible barriers included "being told directly by a senior colleague to withdraw one's candidacy for tenure, or by an associate dean that 'We do not want you to contribute your time and efforts to help in the development of the new journal you established under the grant'" (68). Invisible barriers involved subtle and indirect actions and omissions that undermined personal and professional development, such as being burdened with committee work, left out of the information loop, and not being mentored. Differences in invisible barriers have also been reported in the areas of service and guidance by intersecting race, ethnicity and gender identity. Scholars contend that in order for women to convey professionalism they must embody appropriate professional signals (Bell and Nkomo 2003) or manage "dual femininities" due to racialized gendered boundaries as in the case of Chicana attorneys (GarcíaLópez and Segura 2008). Moreover, "doing" the professional role often requires one to perform both masculinity and Whiteness (Carbado and Gulati 2013; Rivera, Forquer, and Rangel 2010; Cheney and 
Ashcraft 2007). Studies show that Black female faculty were more likely than Black males to report that faculty meetings and committee work were sources of stress, were more likely to give academic and personal support to their students (Griffin , Bennett, and Harris 2011a), were less likely to agree that colleagues in their department valued their research or teaching (Griffin et al. 2011b), and more likely to such as "expectation" and "pressure" to describe service obligations than words like use words such as "expectation" and "pressure" to describe service obligations than words like "volunteer" and "voluntary." High service demands and scrutiny, combined with assumptions of illegitimacy may also contribute to the daily policing of their appearance (Costello 2004) and their own hyper-vigilance about the presentation of sensitive materials in their classrooms which seemingly help them cope and minimize the assaults on their credentials and authority.

Building on this corpus of work that shows systemic exposure to institutional racism results in deleterious effects, we assess the ways URM faculty defines and interprets their institutional experiences. Emphasis is placed on the ways that systemic processes in the university - e.g., expectations for diversity service, and the value attached to various types of scholarship - can adversely affect URM faculty (Wingfield and Feagin 2012; Bell and Nkomo 2003; Browne and Misra 2003). While prior research establishes a context for the strong presence of multiple forms of institutional racism in academia, we attend to the ways in which the institutional climate facilitates an inhospitable workplace, and consider how URM faculty responses and reactions to these slights are informed by their coconstituted, historically situated identities (Ridgeway 2014; Hill-Collins 2015). This study fills a gap in the literature on discriminatory practices and attitudes of academic professionals, and compares the experiences of three distinct historically underrepresented groups. These data can inform institutional policies and practices to create more inclusive and welcoming climates that will increase the presence and retention of URM faculty. To our knowledge this is the first study that includes a significant sample of three URM groups of prestigious professionals, the professoriate, and socioeconomic status data on family of origin.

\section{Methods}

Data are drawn from a mixed methods study of URM faculty at research-extensive PWI. Three sources of data are employed: web-based survey responses $(n=485)$; individual and group interviews $(n=58)$; and survey comments. Conducting a mixed methods study allowed us to construct a more coherent narrative by employing the qualitative data to provide prototypical quotes of lived experiences to interpret discrimination scores, decipher how these experiences may affect respondent career path, and garner insights into intersectional co-constitutive identities in relation to the complex, yet invisible, normative structures of power and discrimination in higher education. Mixed methods are particularly

This article is protected by copyright. All rights reserved 
suited for research on complex organizational contexts and understudied populations, and in conjunction with an intersectional lens, have the potential to generate findings to inform institutional change (Grace 2014; Creswell, Shope, Plano, and Green 2006; Castro et al. 2010).

Eligibility criteria for inclusion were: U.S. born individuals of African American, Mexican American/Chicano/a, and Puerto Rican descent, who held tenure-track assistant or tenured associate professor faculty positions. All were employed in high or very high research extensive universities as defined by the Carnegie criteria (McCormick and Zhao 2005). These specific racial/ethnic groups are considered underrepresented due to their historical and contemporary underrepresentation in the academy relative to their proportion in the general U.S. population. These groups share involuntary historical incorporation into the U.S. (via slavery, colonization, or territory acquisition) that have shaped avenues of economic and social opportunity over time and their social status. Criteria for selection were very specific as the subjects' lives have been deprivileged by their historic intersectional identity (HillCollins, 2015; Rideway, 2014). We aimed to gain information about contemporary faculty career advancement issues. Thus, adjuncts, lecturers, and full professors were excluded based on an analytic decision that adjuncts and lecturers hold temporary teaching positions and full professors have already completed the tenure and promotion process successfully. All participants were identified through network sampling techniques using existing academic listservs, university websites, personal contacts, Faculty Advisory Board members, word of mouth, and respondent referrals. Written consent was obtained from all participants, and those who agreed to individual and group interviews were compensated for their time via small gift incentives.

\section{Procedures, Instruments and Measures}

A web-based survey using standardized instruments was emailed to URM faculty across the United States with informed consent protocols. Data were obtained on demographics (e.g. gender, age, annual individual income, educational background, employment descriptors including geographic location, number of URM in their department, academic rank, and discipline). A 6-item Perceived Gender, Race/Ethnicity, and Class Bias Scale measured perceived bias and discrimination in professional advancement. Respondents were asked whether in their professional career they have ever encountered gender, racial/ethnic, and/or class discrimination by a superior or colleague. Additionally, respondents were asked whether in their professional career they "were ever left out of opportunities" for professional advancement based on gender, race/ethnicity, and/or class. Responses were coded on a 3-point scale that ranged from 1=never; 2=sometimes; and 3=often/always. A cognitive appraisal scale asked respondents to rate how upsetting these experiences were on a 3-point scale (1=extremely/very

This article is protected by copyright. All rights reserved 
upsetting; $2=$ mildly upsetting and $3=$ not upsetting at all). Cronbach alpha reliability tests were conducted for the total web-based survey sample $(\alpha=.900)$ and by race and ethnicity $(\alpha=.907$ for African Americans and $\alpha=.887$ for Mexican Americans and Puerto Ricans).

The qualitative phase of the study included 37 face-to-face interviews and 21 group interviews. Group interviews were organized by race/ethnicity and gender and each participant answered all questions. For example, we conducted a Mexican American male group and an African American female group. The 58 respondents also completed a survey protocol with comparable demographic, employment and discrimination scale items used the web-based surveys. Qualitative data protocols consisted of 20 open-ended questions adapted from prior instruments (see Higginbotham 1990; Turner, González, and Wood 2008; Trower 2009; Zambrana, Dorrington and Bell 1997). For this paper, we used the responses to the following four questions: What types of incidents have you observed in the workplace that you consider racial/ethnic or gender discrimination?; Have you ever experienced racism and/or gender discrimination in the work environment?; Two additional questions asked respondents to describe three institutional challenges that most hindered, and three challenges that "most helped their career path and advancement." These questions provided a deep understanding of examples of incidents of discrimination and racism. Web-based survey comments, which provided detailed narratives of workplace experiences of discrimination, are noted.

\section{Data Analyses}

All respondents from web-based and individual and group surveys were combined yielding a total analytic sample of 543 participants by self-reported race and Hispanic subgroup. Descriptive analyses (frequencies, proportions and means) were derived for all sociodemographic and employment variables and the discrimination scale. Coding of qualitative data was completed in Atlas.ti 6.2 to allow for more efficient analysis and interpretation.The initial coding scheme, developed by the first author, was based on pilot interviews and a comprehensive literature review. Each transcribed interview was coded, line-by-line, by two trained qualitative coders independently and then disagreements in coding were reconciled by a $3^{\text {rd }}$ independent coder. We adhered to a process of synchronizing data with research questions that depend on a "conditional matrix" which allows the researcher to continually ask how, for example, gender, race, ethnicity, and socioeconomic status impact the experiences of respondents (Strauss and Corbin 1998:165). (A fuller description of the methods is described elsewhere; see Zambrana et al. 2015).

\section{Study Limitations}

These data are limited by the cross-sectional study design, the voluntary nature of the This article is protected by copyright. All rights reserved 
participants, and potential selection bias as many participants were identified by a network known to the first author. It is possible that those who either felt well-suited to academia or, by the same measure, totally dissatisfied, elected not to participate. Participants may also have provided socially desirable responses because they feared the consequences of disclosure to the interviewers who were senior faculty members. Other factors that may have influenced experiences include colorism and phenotype, philosophic and political orientation, higher socioeconomic status of family of origin, and geographic location. Further, nonrandom sampling procedures and sample size do not permit causal inference and may not be representative of all URM faculty in academic settings. Thus, we do not present statistical tests of differences to prevent readers from erroneous inferences. We highlight the patterns and experiences of our sample. Significantly, Native Americans/American Indians, who are severely underrepresented in higher education, are not included in this paper. Nonetheless, we are confident that our data provide insight into the perceived discriminatory experiences of a diverse crosssectional sample of URM faculty at PWI.

\section{Sample Description}

Respondents were 61\% African American ( $n=333)$, 24.6\% Mexican American ( $n=134)$, and 14\% Puerto Rican ( $n=76$ ) with more women (61\%) than men comprising the total sample. The mean age of the participants was 42.8 years. The sample included more assistant than associate professors $(59.4 \%$ vs. $40.6 \%$ ). In terms of marriage, $67.8 \%$ of respondents were married or living with a partner and about one fifth (20.1\%) of the respondents reported never being married. Forty-four percent of the sample reported no children. With respect to income, about 50 percent of the total sample reported earning $\$ 90,000$ or more annually. The majority of the sample, 70 percent, reported home ownership. The sample was equally distributed (about 20\%) across five regions of the country: Northeast, Mid-Atlantic, Southeast, Midwest, and Southwest/West. About 40 percent of all respondents reported two or less URM faculty members (including themselves) in their academic department, while slightly over one third (35.7\%) reported 3-5 URM faculty members.

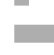

Table 1 displays the descriptive statistics by race, Hispanic subgroup ethnicity, and gender on the 6-item perceived racial/ethnic, gender, and class bias scale and the discrimination impact score measuring how upsetting these incidents were. Of the total sample, $44 \%$ report racial/ethnic discrimination, 30\% report gender discrimination "often/always" by a colleague or superior and almost one-quarter (23\%) report class discrimination. Closer observation reveals differences by race, ethnicity, and gender across groups. The patterns reveal the following: women are more likely than men to report 
both racial/ethnic and gender discrimination. Puerto Rican women are more likely to report class discrimination than the overall sample. Mexican American and Puerto Rican women report higher perceptions of gender and race/ethnic discrimination than African American women. Mexican American men are least likely to report gender discrimination while about one-fifth of Puerto Rican men report gender discrimination. About two in five African American and Puerto Rican men report race/ethnic discrimination "often or always" by a superior or colleague. Particularly noteworthy, Puerto Ricans report the highest percentages of class discrimination followed by Mexican Americans overall.

[Table 1 About Here]

Three items asked respondents about perceptions of being "left out of opportunities based on gender, or race/ethnicity and/or class." We observe distinct gender patterns with women being more likely than men to report being left out of opportunities "often/always" based on gender and race/ethnicity. African American women were more likely to report racial/ethnic discrimination and less likely to report being left out of opportunities based on class, compared to Puerto Rican and Mexican American women. African American men are more likely to report "being left out of opportunities" based on race/ethnicity compared to Puerto Rican and Mexican American men. Mexican American men are the most likely to report "being left out of opportunities" based on class.

Out of a total score of 18 , the mean sample discrimination scale score was 11.45 , confirming patterns observed above by gender and race/ethnicity. The item on how upsetting these incidents were shows that just under half (47\%) reported discrimination incidents to be extremely/very upsetting. Gendered breakdowns within each of the three URM groups highlight the variations in experiences along the intersections of race/ethnicity and gender. Women had higher mean discrimination scores than their male counterparts with Mexican American women having the highest mean score. Mexican American women (58\%) and African American women (51\%) were the most likely to report these incidents as "extremely/very upsetting." The least likely to report the incidents as upsetting were African American men (40\%) and Mexican American men (39\%) which we speculate could represent a "normalizing" of daily microaggressive encounters. Overall, data show that respondents are most likely to report experiencing overall racial/ethnic discrimination and are most likely to report being left out of opportunities based on race/ethnicity rather than gender or class.

While URM faculty largely experience the academy as an unwelcoming environment, the extent to which this is the case and the toll it takes varies by intersectional race/ethnic, gender, and class,

This article is protected by copyright. All rights reserved 
status. Although scale data provide an overview of the frequency of discriminatory experiences and perceived level of impact, what is not revealed by numeric data is the context and types of incidents that can be categorized as discriminatory practices. Individual and group interview data yield insightful narratives on how respondents experienced and witnessed discriminatory practices in White spaces.

Interpretative Context: The Lived Experiences of Discriminatory Practices

Discrimination has many expressions fueled by unintentional, implicit and unquestioned assumptions. The respondents provided descriptions of a range of discriminatory incidents around three themes: blatant, outright, subtle, and insidious racism; devaluation of their scholarship and credentials; and a "representing" burden or a "racial/ethnic tax" (Griffin et al. 2011a). Quotes were selected that captured the sentiments of the majority of the respondents. Importantly, the narratives reveal that many of the discriminatory processes respondents encountered persist across racial/ethnic, gender and class lines.

\section{Racism: Blatant, Subtle and Insidious}

Many respondents reported outright, blatant discriminatory practices while some respondents reported more subtle and nuanced forms of racism that made it difficult to assess whether they were actually experiencing racism or what identity status was responsible for the discrimination they were facing. Overt examples indicated a strong lack of knowledge, awareness, and sensitivity among nonURM colleagues at their institutions and an overall degree of tolerance for blatant racism at the departmental and institutional levels. The following two quotes illustrate this point:

So [a professor] called me in his office and this was - I was stunned. He said well, first I need to let you know I can't deal with the black thing. He said I'm from the rural South..... and I still have some prejudices. (African American, male)

I was on the search committee with some [faculty], and my friend and colleague's name was in the pool. And so one of the White colleagues said, "Oh, wow. He's a Black guy and he can do math." And I was like, "Why do you think that's okay to make a statement like that?" (African American, female)

Discriminatory experiences of observing exclusionary and quota system practices on one hand, and a diversity rhetoric on the other, take a powerful toll on the emotional resources of respondents. The emotional labor invested in witnessing and coping with these practices creates a productivity taxation that 
indubitably effects retention, tenure, and promotion. These encounters occur on a regular basis. One respondent describes her experience on a faculty search committee. She states:

I was one of five members on the committee, and the most racist person in the department was selected to chair the committee. I don't know why. But he said to us, in a closed committee meeting, at the very beginning of the search, that we did not need to really consider any of the African American candidates, because as a university in the south, we were already over-serving Black people. (Mexican American, female)

This narrative is repeated by many participants. It can be referred to as the "minimum "approach. The resistance to hiring more than one underrepresented minority in a department is outright discrimination, yet tolerated by many faculty. One respondent discusses how we need "to stop the quota system on us." She states:

In the department that I was in with the fellow Latino faculty member, somehow two Latino faculty members is enough. Well, why is it that two Latino faculty members is enough and it's not enough to have 15 White faculty members? So, on the one hand, they're saying, "Well, you know, we can't use quotas," but on the other hand, "Oh, you know, you've already got two. Why do you want another one?" So, .... understand the racial dynamics of that. (Puerto Rican, female)

The quota systems for URMs tend to occur in traditional disciplinary fields (rather than in racial/ethnic studies) where the "only one" syndrome prevails in a department or even a college. This can lead to URM faculty being clustered in ethnic studies fields, undermining institutional efforts to foster diversity and inclusion. In other words, if White faculty in various departments police hiring and artificially decrease the numbers of URM professors in their areas, it suggests that diversity is not valued across the board and that bias and stereotypic, implicit assumptions prevail. These assumptions may include that URM faculty are best suited for specific fields of study rather than being qualified intellectuals in a wide array of subjects. These data provide insight into the continued sparse representation of URMs in higher education and the resistance to hiring additional URMs in departments where there is already some representation. Importantly, while respondents attribute different causes to the perceived exclusionary behavior, common discriminatory practices are reported to be widespread and fairly universal in academia.

This article is protected by copyright. All rights reserved 
Many respondents perceived their workplace environment as hostile or not responsive to their career aspirations. For example, many reported feeling like there is no one in authority who can provide help and all too often felt that they had to resign themselves to accept certain situations. One respondent observed:

...the environment, in many regards, is more than hostile. And no one - and even the dean said even if my environment is less than ideal, what can he do to change it. He said people are treating me different than others. He said there's no policy that he can implement to make things better, even as dean of the school. If people are treating me differently than others, he couldn't - he can't do anything about it, so accept it. (African American, male)

Similarly, another African American male reflected on the institutionalized inequitable treatment of URM faculty:

With the pay, the other folks whose pay are all substantially higher than mine are all White. So other folks' pay have been adjusted, all White, who have gone in and talked with the chair, et cetera. I go in and make the same type of pleas, but I'm told, "You showed up on our doorstep looking for a job." So that's definitely not gender. I think that is more than likely race based... (African American, male)

These narratives serve as a powerful reminder that blatant and outright racism are part of the everyday experiences of URM faculty in academia.

Yet, not all faculty could conjure up clearly discriminatory experiences or reported that incidents were ignored. While respondents perceived both outright racism and blatant microaggressions, there were also incidents that were described as more subtle. When asked about their experiences of discrimination, some of the participants struggled to name and identify experiences as racism or discrimination. Often times their experiences were described as "subtle, nuanced, and insidious." A Mexican American male discussed the multilayered microaggressions on his campus:

Instances of racism are really hard to pin down, because they're so complex. I think, to some degree, the criterion that is used to assess students before they get admittedthat's what? Institutional apparatus...The one thing I think, in terms of racism or discrimination or prejudice in the academy that I've noticed in our

This article is protected by copyright. All rights reserved 
department...whenever we were discussing candidates for the positions, one phrase that would consistently pop up, when people, I would argue, were being prejudiced or discriminatory, was "quality of mind." So that sort of would be used as a phrase to assess somebody who didn't meet the rigorous set of standards and expectations that the academy must abide by. Usually, they were candidates of color. They would start talking about these aspects, but "quality of mind" would be the term.

An African American female discussed her work environment as toxic yet stated that since microaggressions were NOT blatant, they were ignored. She states:

The environments in which we work are hostile, less than supportive, and infected with various microaggressions. These types of assaults, which are done by students and colleagues, ARE very demoralizing and are ignored by superiors because they are not blatant. However, they are toxic to the minds and spirits of minorities within academe who love our careers but find the environments in which we work less than supportive. (Web-Based Survey Comments, African American, female, emphasis in original)

In response to these microaggressions, respondents reported fear of being accused of using the "race card" and thus preferred to identify race/ethnic assaults as subtle and nuanced yet insidious. Respondent narratives reveal an institutional space that is heavily invested in normalizing "Whiteness" as a marker of authority, qualification, and suitability for faculty work, and conversely a highly racialized hierarchy. One African American male describes the White space in the following way:

"In our department there kind of is the - the professors who are distinguished or so on, they're seen as these White professors, right? And so students, many of these White students in particular who come to the program are-they're here to work with these White professors. And so there's that idea that the only good researchers, scholars in our program are White. And that's the way the White professors act as well."

Consequently, respondents report being witness or subjected to statements on a regular basis that suggest that their racial/ethnic status - and that of other candidates for faculty positions - marks them as distinct, different, and unable to fit or integrate fully into the institutional structure. These derogatory

This article is protected by copyright. All rights reserved 
comments regarding qualifications of a URM student or faculty undermine a sense of belonging and inclusion in the university.

\section{Manifest through Devaluation of Accomplishments}

Respondents observed that one of the ways that discrimination and racism manifests is through the devaluation of accomplishments and credentials as well as the questioning of the competence and successes of URM faculty. Perceptions of discrimination, such as the presumption of incompetence, emerged in the narratives, including suggestions that URM faculty were "target of opportunity" hires; were going to need extra help; and their credentials were not meritorious enough. Respondents were often unsettled by colleagues' explanations for their presence. The following quotes highlight these incidents:

But most of the time, in my work settings, I think it's been more of the, "Oh, wow, you can actually do this job, even though you're [Chicano, etc.]," which I don't know if that's racism. I think it is. (Mexican American, female)

I believe in affirmative action. I think it's necessary and yet I think it's a double-edged sword. Because if you get into a good school, people say, "Did you get in because you're an affirmative action person?" You know, it's okay to be a legacy person, a legacy admit, but it's not good to be an affirmative action admit. Or is it, "Are you really as good as us, or are you just here because of affirmative action?" (Mexican American, female)

Another African American female respondent speaks to indirect devaluing but with serious embedded group-driven racial overtones. She states:

So the day I quit we were having a meeting, the guy who thinks he is best friends with me said to me: "You know, I just really think that once we get this achievement gap thing under wraps or whatever, America can move forward. Once we get those Black kids achieving, America can really meet its potential." I was like Wow. So I just got up, left and never came back.

Devaluing is an especially pernicious discriminatory practice. It is a historic, stereotypic perception that is structurally embedded in the normative institutional climate. These narratives affirm the importance of disaggregating the multiple categories of diversity and critically attending to co-constituted identities

This article is protected by copyright. All rights reserved 
that are inscribed into institutional perceptions in detrimental ways: either that URMs get a position due to their race/ethnicity rather than merit; and /or have a position whereby they are expected to represent the entire racial/ethnic group.

\section{Representing Diversity Burden and Racial/Ethnic Tax}

URM faculty face tremendous pressure to "represent" and to engage in service and committee activities that require significant sacrifices of their time in addition to teaching and mentoring URM students, because they are often the one person on campus who can "check the box" (see also Wingfield 2013). As the sole URM representative on committees or in meetings, URM faculty face the pressure to represent the voice of diversity and/or the indignity of being expected to speak for all URM students or faculty. Faculty recognizes that there is an inequitable division of service work and that while they are expected to carry the greater load, these activities are not rewarded or accorded value during promotion and tenure review. These events are also indicative of institutional racism. Such marginalized work is not expected of White faculty members because it is not considered important. Many respondents spoke about the burden of diversity work. Two in particular capture the sentiment and voice of respondents regarding this topic:

She [administrator] emails me and the other black professor. There are only two of us in the whole school. .... and she says, "I'm meeting with such and such on this day for lunch and l'd like for you to join us." Well it's summer. We're not employees of the University in the summer. In the e-mail she said he does something with diversity. Well one thing that's nice in our school is that there are quite a few people who "do diversity," other types of gender primarily, disability and employment. So we have quite a cluster of people who "do diversity." ........ we do race primarily. So I just gently reminded her, "There are other people-there are many other people in the school who do diversity. So you might consider inviting them." So then she calls me and badgers. She's just like, "I need you to do this. Well the Dean is expecting you to do stuff like this and I'm going to have a conversation with him." Then finally she just - "Look, he's black. I'm going to have to talk to this guy and it's just going to be me and this other White woman and I need somebody there." I'm like, "You have broken so many laws it's not even funny." Of course I don't say this to her but I'm like, "You know what? I cannot make it. I'm really sorry." (African American, female)

This article is protected by copyright. All rights reserved 
How our colleagues are treated at this institution has a huge toll on the rest of us. Less brown/black faces also means more work for the rest of us that are here. The negative racial climate on my campus results in emotional tolls as well as serious drains on our time. (Web-Based Survey comments, African American, female)

A significant corpus of work has illuminated the normative expectations that URM faculty "do the work" of diversity, particularly in PWI where URM faculty are the most severely underrepresented. Although race/ethnicity was reported as a major barrier to a sense of belonging, it oftentimes served as the university's trump card for embracing diversity. One Mexican American male describes eloquently the dilemma for URM faculty and the benefits to the institution:

But the institutional challenge, on the other hand, is that we have a dean who has been around for a while, who there is a consensus among most under-represented faculty, that she doesn't value diversity unless it can look good on paper or can be used as a vehicle for getting money from someone.

While such diversity work is deemed extremely valuable to the overall institution, its benefit and value to the career path of URM faculty is minimal in the tenure and promotion process. While this puts a significant additional burden on URM faculty it also has a significant impact of "freeing" up White faculty from "diversity" work and allowing them to focus on work that has value for tenure and promotion.

The data presented here reveal an especially injurious dynamic within everyday processes in the university environment and the ways in which they are racialized. In as much as URM faculty are stereotyped as undeserving, unskilled, and unsuited for faculty positions, they are also highly visible and exposed because of their racial/ethnic status. Their heightened visibility makes them very conspicuous when it comes to university service. The emotional labor required to confront frequent microaggressions combined with demanding diversity service may partly explain the lower retention rates of URM academics.

\section{Discussion and Conclusions}

The data reveal three important findings on experiences of discrimination across race/ethnic groups: 1) significant levels of outright, blatant and subtle race/ethnic discrimination; 2) devaluing of competency and merit coupled with an injurious burden of excessive diversity work; and 3) URM Latino participants reported higher gender and class discrimination than their African American counterparts. Our study provides unique insights into discriminatory practices prevalent in PWI and illuminates the particular ways that URMs encounter the effects of institutional racism from colleagues This article is protected by copyright. All rights reserved 
and supervisors. The language used by respondents highlights the difficulties associated with identifying and describing racialized practices in a context where the dominant discourse is one of "color-blindness" and "post-racialism" (Bonilla-Silva 2009). Although URMs have gained entry into faculty and administrator ranks, our findings confirm that respondents continue to experience barriers to full inclusion within academic institutions and experience a variety of microaggressions, including implicit and explicit racism and discrimination, a sense of isolation — and a devaluing of their research, which can negatively affect physical and mental well-being (Lewis et al. 2015; Araujo and Borell 2006; Mays, Cochran, and Barnes 2007; Williams and William-Morris 2000) and the rate of workplace retention (Alex-Assensoh 2003; Allison 2008; Hassouneh et al. 2014; Robinson 2014; Rockquemore and Laszloffy 2008).

Despite some public perceptions of academia as a liberal bastion, respondents report feeling like outsiders and interlopers in the workplace due to blatant, outright and insidious forms of institutional racism that permeate their daily lives. Yet respondents also report difficulty in describing their experiences, as the manifestations of racism are more covert and reflect "colorblind" racial ideology (Bhopal and Jackson 2013). Perceived discrimination has been interpreted as: subjective; hypersensitivity on the part of the historically underrepresented person; and/or an unintended comment that meant no harm. Whites often dismiss racially problematic statements or actions as simple jokes or unimportant asides to which minorities - and some Whites - overreact (Picca and Feagin 2007). Although many respondents describe interactions and behaviors that reflect racialized stereotypes, biases, and cultural assumptions, they express doubt and uncertainty about labeling these as race-associated interpersonal and institutional practices. They encounter colleagues and supervisors who suggest that their racial/ethnic status makes them unqualified and unintelligent and experience a crisis of legitimacy as a result, yet simultaneously express discomfort at the idea of attributing these processes to racial dynamics. Though much of the literature on race/ethnicity discusses the ways that shifting paradigms have created complicated rhetorical language and discourses around issues of race and inequality (see Bonilla-Silva 2009; Valdez 2015), these studies often focus on the ways Whites are unable to reconcile declarations of "colorblindness" with statements that reflect racial stereotypes and a desire to maintain their privilege. Despite being on the receiving end of various manifestations of racial/ethnic inequality, respondents also express ambiguity about whether these instances genuinely qualify as racism, which perhaps serves as a protective mental health mechanism. Myths abound in the master narratives that URM individuals are quick to "play the race card," yet this study demonstrates that they may be less likely or willing to identify disparate treatment as racist or discriminatory.

This article is protected by copyright. All rights reserved 
Ultimately, the unwillingness and inability to identify racist practices likely contributes to the perpetuation of such practices, and makes cessation difficult. These data may also suggest the presence of avoidance behavior, particularly among men, as a critical strategy of survival, resistance, and selfprotection, given that tenured faculty must work with their department colleagues, often for extended periods of time.

Across racial/ethnic groups, females overall report higher percentages of all forms of discrimination and unequal treatment than their male counterparts; Mexican American and Puerto Rican women are more likely to report all three types of discrimination compared to African American women; and "Being left out of opportunities" was attributed predominantly to race/ethnicity. Notably, Puerto Ricans and Mexican Americans were more likely than African Americans to report class discrimination, which may be associated with these Latino subgroups being more likely to be the first in their families to graduate high school and complete college (Hurtado et al. 2008) and experience heightened sensitivity to degrading discriminatory practices. In this study over $55 \%$ of African Americans had mothers and fathers who had completed graduate degrees compared to about $12 \%$ of Latino subgroup parents who had completed a graduate degree. Thus, it may be that class privileges conferred greater social capital and cultural resources to African American faculty than their Latino counterparts, enabling them to navigate professional workplace settings more effectively (Bourdieu 1986; Lareau 2000).

A modest but significant body of knowledge has demonstrated that URM women specifically compared to URM men report higher role overload, higher expectations to be available to students and perceive strong pressures to engage in "diversity service" (Harley 2008; Lugo-Lugo 2012; Niemann 2012). Yet, they often perform their roles under the guise of "presumed incompetence" (Gutiérrez y Muhs et al. 2012). African American and Mexican American women report the most upset by these incidents, while African American and Mexican American men report the lowest levels of upset. These gender differences may suggest higher work demands for women, or a higher sensitivity to these issues. Data may also suggest that males are less likely to report discrimination and racism due to not wanting to complain or a learned ability to cope by ignoring daily incidents of racism. Anecdotal data and other studies have found that URM men frequently face misidentification and suspicion of not belonging in a White space (Nadal et al. 2014; Smith, Yosso, and Solórzano 2007; Wingfield 2013). These data provoke the question: are URM men compared to URM women more protected in academic workplace settings? Noteworthy observation is that more women than men are graduating from college and they outnumber men in college faculty (in 2013, African American females represented $6.8 \%$ of faculty vs 
4.3\% males and Latino women represented $4.5 \%$ vs 3.9\% males) (U.S. Department of Education 2015). Further research inquiry regarding whether institutional racism is a deterrent to academic careers for URM men is called for to explore how institutional racism manifests itself in the lives of URM males and its impact on their retention.

A plethora of evidence demonstrates that racism and all its manifestations are an integral part of workplace settings, especially higher education institutions (Essien 2003; Moore 2008; Wingfield and Alston 2014). These findings lend support to Hill-Collins' (2015) assertion that intersectionality can help illuminate power relations, as well as to Lewis, Cogburn, and Williams' (2015) contention that intersectional factors are understudied but matter in shaping discrimination. By showing the ways that discrimination is experienced intersectionally rather than uniformly across racial/ethnic groups, this paper highlights key differences in the ways various groups may understand and attach importance to mechanisms that maintain their marginalization in academia. Institutional racism presents a heavy burden for URM faculty that results in daily vigilance and anticipatory stress. Respondents experience anger, frustration, doubt, guilt, or sadness when they encounter microaggressions, as well as feelings of distress when relaying their stories (Sue et al. 2008). Yet, their emotional responses are carefully policed in these work environments (Wingfield 2010). We argue that these experiences create a productivity taxation due to the emotional labor required to sustain racialized assault with disciplined or no response. These racialized experiences impact productivity and the ability to navigate academic demands and may be associated with lower retention rates.

To potentially ameliorate the challenges facing URM faculty (Bhopal and Jackson 2013; Whittaker, Montgomery, and Acosta 2015), many universities express a commitment to building a diverse faculty and will often mention in recruitment ads that they enthusiastically welcome applications from underrepresented minorities (Zanoni et al. 2010). However, the findings shed light on the challenges associated with both recruitment and retention. In as much as, historically, racial/ethnic minorities with multiple social statuses of historic disadvantage or intersectionalities report increased stress associated with discriminatory behaviors from their White colleagues, universities need to devote greater attention to creating more hospitable work environments for their URM faculty. Bland statements about welcoming and appreciating diversity are not sufficient to counteract the behaviors that create inhospitable environments (See Acosta-Belén and Bose 2012; Moreno et al. 2006). However, university leadership can use this opportunity to reward the creation of equitable work environments in colleges, schools, departments, and programs.

This article is protected by copyright. All rights reserved 
Universities can take specific steps to make the campus culture and climate more welcoming including, for example, leadership development, safe spaces for professional skill development and mentoring committees. The cultivation of URM faculty in administrative leadership positions committed to ensuring equitable treatment in hiring practices such as cluster hiring, promotion and tenure processes, and service expectations can promote more hospitable institutional practices (Moreno et al. 2006). Commitments must be expressed verbally, both within the university and in the public eye, through policy, and embedded in the unspoken university culture (University of California Hastings College of the Law, n. d.). Other important recommendations include providing safe skill-building spaces for publication and grant development. A recent approach that has proven successful is a one-week training Intersectional Qualitative Research Methods Institute (IQRMI) for URM scholars at the University of Maryland in methods and navigation skills in inhospitable environments. IQRMI aims to validate the research agendas of early career faculty, and provide safe intellectual space and ways to counteract prior negative experiences to enhance career success

(www.crge.umd.edu/iqrmi/index.html). Another potential solution is the development of mentoring launch committees for URM faculty. These programs require full support at the institutional and departmental level and include the chair of the department, an external member, a senior colleague who is interested in the mentee's work and a departmental senior colleague. In these committees, mentors are selected to promote their mentees' ideas, intellect, political wisdom and professional commitments (Thompson 2008; Zambrana et al. 2015). Moreover, incentives (economic or release time) must be part of a program in which URM faculty are linked with senior colleagues who can provide advice, feedback, and training, a strategy that has shown moderate success in corporate settings (Kalev, Dobbin, and Kelly 2006) and foundation sponsored academic programs. These efforts could go a long way to offset the discriminatory experiences described in this paper, as well as contribute to a shared effort for institutional change, higher retention rates and a sense of belonging.

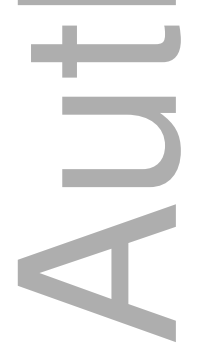

This article is protected by copyright. All rights reserved 


\section{References}

Acosta-Belén, Edna and Christine Bose. 2012. Unfinished Business: Latino and Other Faculty Diversity in the SUNY System. New York, NY: NYLARnet.

Agathangelou, Anna M. and L. M. H. Ling, 2002. “An Unten(ur)able Position.” International

- Feminist Journal of Politics 4(3): 368-398.

Alex-Assensoh, Yvette. 2003. "Race in the Academy: Moving Beyond Diversity and Toward the Incorporation of Faculty of Color in Predominantly White Colleges and Universities." Journal of Black Studies 34(1): 5-11.

Allison, Donnetrice C. 2008. "Free to be Me?: Black Professors, White Institutions." Journal of Black Studies 38(4):641-662.

Araujo, Beverly Y. and Luisa Borell. 2006. “Understanding the Link between Discrimination, Mental Health Outcomes and Life Chances among Latinos." Hispanic Journal of Behavioral Sciences 28:245-266.

Bell, Ella L. J. Edmondson and Stella M. Nkomo. 2003. Our Separate Ways: Black and White Women and the Struggle for Professional Identity. Harvard Business Review Press.

Bell, Sandra, Marina Marrow, and Evangelia Tastsoglou. 1999. "Teaching in Environments of Resistance: Toward a Critical, Feminist and Antiracist Pedagogy." Pp. 23-48 in Meeting the Challenge, edited by M. Mayberry \& E. Rose. New York: Routledge.

Bonilla-Silva, Eduardo. 2009. Racism without Racists: Color-blind Racism and the Persistence of Racial Inequality in America. Lanham, MD: Rowman \& Littlefield.

Bhopal, Kalwant and June Jackson. 2013. "The Experiences of Black and Minority Ethnic Academics: Multiple Identities and Career Progression." Retrieved September 30, 2015 (http://blackbritishacademics.co.uk/wp-content/uploads/2013/04/Research-Report-TheExperiences-of-Black-and-Minority-Ethnic-Academics-Dr-Bhopal.pdf).

Bourdieu, Pierre. 1986. "The Forms of Capital." Pp. 241-258 In Handbook of Theory and Research for Sociology of Education, edited by J. G. Richardson. New York, NY: Greenwood Press

Browne, Irene, and Joy Misra. 2003. "The Intersection of Gender and Race in the Labor Market." Annual Review of Sociology 29:487-513.

Carbado, Devon and Mitu Gulati. 2013. Acting White? Rethinking Race in "Post-Racial "America. New York, NY: Oxford University Press.

This article is protected by copyright. All rights reserved 
Castro, Felipe G., Joshua G. Kellison, Stephen J. Boyd, and Albert Kopak. 2010 "A Methodology for Conducting Integrative Mixed Methods Research and Data Analyses." Journal of Mixed Methods Research 4(4): 342-360.

Cheney, George and Karen Lee Ashcraft. 2007. "Considering 'the Professional' in Communication Studies: Implications for Theory and Research Within and Beyond the Boundaries of Organizational Communication." Communication Theory 17(2):146-175.

Costello, Carrie Y. 2004. "Changing Clothes: Gender Inequality and Professional Socialization." NWSA Journal 16(2):138-155.

Creswell, John W., Ron Shope, Vicki L. Plano Clark, and Denis O. Green. 2006. How Interpretive Qualitative Research Extends Mixed Methods Research. Research in the Schools 13(1): 1-11.

Essien, Victor. 2003. "Visible and Invisible Barriers to the Incorporation of Faculty of Color in Predominantly White Law Schools." Journal of Black Studies. 34(1):63-71.

Feagin, Joe R. 2006. Systemic Racism: A Theory of Oppression. New York, NY: Routledge.

---- 2013. The White Racial Frame: Centuries of Racial Framing and Counter-Framing, 2nd edition. New York, NY: Routledge.

García-López, Gladys and Denise A. Segura. 2008. "They are Testing you all the Time": Negotiating Dual Femininities among Chicana Attorneys." Feminist Studies 34(1/2): 229-258.

Grace, Daniel. 2014. "Intersectionality-Informed Mixed Methods Research: A Primer." The Institute for Intersectionality Research and Policy, SFU, Retrieved September 30, 2015 http://www.sfu.ca/iirp/documents/resources/MixedMethodsPrimer_Final_v4.pdf.

Griffin, Kimberly A., Jessica C. Bennett, and Jessica Harris. 2011a. "Analyzing Gender Differences in Black Faculty Marginalization Through a Sequential Mixed-Methods Design." New Directions for Institutional Research 151: 45-61.

Griffin, Kimberly A., Meghan J. Pifer, Jordan R. Humphrey, and Ashley M. Hazelwood. 2011b.

“(Re)Defining Departure: Exploring Black Professors' Experiences with and Responses to Racism and Racial Climate." American Journal of Education 117:495-526.

Gutiérrez y Muhs, Gabriella, Yolanda Flores Niemann, Carmen G. González, and Angela P. Harris, eds. 2012. Presumed Incompetent: The Intersections of Race and Class for Women in Academia. Boulder, CO: University Press of Colorado.

Harley, Debra A. 2008. "Maids of Academe: African American Women Faculty at Predominately White Institutions." Journal of African American Studies 12:19-36

This article is protected by copyright. All rights reserved 
Harlow, Roxana. 2003. “'Race Doesn't Matter, But. . .': The Effect of Race on Professors' Experiences and Emotion Management in the Undergraduate College Classroom." Social Psychology Quarterly 66(4):348-363.

Harnois, Catherine and Mosi Ifatunji. 2011. “Gendered Measures, Gendered Models: Toward an Intersectional Analysis of Interpersonal Racial Discrimination." Journal of Ethnic and Racial Studies 34:1006-1028.

Hassouneh, Dena, Kristin F. Lutz, Ann K. Beckett, Edward P. Junkins, and LaSahwn L. Horton. 2014. “The Experiences of Underrepresented Minority Faculty in Schools of Medicine." Medical Education Online 19:24768.

Henderson, Loren and Cedric Herring. 2013. "Does Critical Diversity Pay in Higher Education? Race, Gender, and Departmental Rankings in Research Universities." Politics, Groups, and Identities 1(3):299-310.

Higginbotham, Elizabeth. 1990. "Designing an Inclusive Curriculum: Bringing all Women Into the Core." Women's Studies Quarterly 1 \& 2:8-23.

Hill-Collins, Patricia. 2015. “Intersectionality's Definitional Dilemmas.” Annual Review of Sociolog, 41:120.

Hurtado, Sylvia, Victor B. Sáenz, Jose L. Santos, and Nolan L. Cabrera. 2008. “Advancing in Higher Education: A Portrait of Latina/o College Freshmen at Four-Year Institutions, 1975-2006." Los Angeles: Higher Education Research Institute.

Kalev, Alexandra, Frank Dobbin, and Erin Kelly. 2006. "Best Practices or Best Guesses? Assessing the Efficacy of Corporate Affirmative Action and Diversity Policies." American Sociological Review 71:589-617.

Lareau, Annette. 2000. "Social Class and the Daily Lives of Children: A study from the United States." Childhood 7(2):155-171.

Lewis, Tene T., Courtney D. Cogburn, and David R. Williams. 2015. "Self-Reported Experiences of Discrimination and health; Scientific Advances, Ongoing Controversies, and Emerging Issues." Annual Review of Clinical Psychology 11:407-440.

Lugo-Lugo, Carmen R. 2012. "A Prostitute, a Servant, and a Customer-Service Representative: A Latina in Academia." Pp. 40-50 356 in Presumed Incompetent: The Intersections of Race and Class for Women in Academia. Edited by Gutiérrez y Muhs, Gabriella, Yolanda Flores Niemann, Carmen G. González, and Angela P. Harris. Boulder, CO: University Press of Colorado. 
Mays, Vickie M., Susan D. Cochran, and Namdi W. Barnes. 2007. "Race, Race-based Discrimination, and Health Outcomes among Blacks." Annual Review of Psychology 58:201-225.

McCormick, Alexander C., and Chun-Mei Zhao. 2005. "Rethinking and Reframing the Carnegie Classification." Change Sept/Oct 2005: 51-57.

Moore, Wendy Leo. 2008. Reproducing Racism: White Space, Elite Law Schools, and Racial Inequality." Lanham, MD: Rowman \& Littlefield.

Moreno, José F., Daryl G. Smith, Alma R. Clayton-Pedersen, Sharon Parker, and Daniel Hiroyuki Teraguchi. 2006. "The Revolving Door for Underrepresented Minority Faculty in Higher Education: An Analysis from the Campus Diversity Initiative." Retrieved March 20, 2015 http://www.cgu.edu/PDFFiles/insight Revolving Door.pdf

Nadal, Kevin L., Silvia L. Mazzula, David P. Rivera and Whitney Fujii-Doe. 2014. “Microagressions and Latina/o Americans: An Analysis of Nativity, Gender, and Ethnicity." Journal of Latina/o Psychology 2(2):67-78

Niemann, Yolanda Flores. 2012. "The Making of a Tomen: A Case Study of Stereotype Threat, Stigma, Racism and Tokenism in Academe." Pp. 336-356 in Presumed Incompetent: The Intersections of Race and Class for Women in Academia. Edited by Gutiérrez y Muhs, Gabriella, Yolanda Flores Niemann, Carmen G. González, and Angela P. Harris. Boulder, CO: University Press of Colorado.

Pager, Devah and Hana Shepherd. 2008. "The Sociology of Discrimination: Racial Discrimination in Employment, Housing, Credit, and Consumer Markets." Annual Review of Sociology 34: 181-209. Picca, Leslie and Joe Feagin. 2007. Two-Face Racism: Whites in the Backstage and Frontstage. New York, NY: Routledge.

Ridgeway, Cecilia L. 2014. "Why status matters for inequality." American Sociological Review 70(1): 1-16. Rivera, David P., Erin E. Forquer, and Rebecca Rangel. 2010. “Micro-aggressions and the Life Experience of Latina/o Americans." Micro-aggressions and Marginality: Manifestation, Dynamics, and Impact, edited by Derald Wing Sue. Hoboken, NJ: Wiley: 59-84.

Robinson, Ora V. 2014. "Characteristics of Racism and the Health Consequences Experienced by Black Nursing Faculty." Association of Black Nursing Faculty 25(4):110-115.

Rockquemore, Kerry A. and Tracey Laszloffy. 2008. The Black Academic's Guide to Winning Tenure without Losing Your Soul. Boulder, CO: Lynne Rienner Publishers. 
Sewell, Abigail. 2015. "Opening the Black Box of Segregation: Real Estate and Racial Health Disparities." Pp. 87-105 in Race and Real Estate A. Brown and V. B. Smith, eds. New York, NY: Oxford University Press.

Smith, William A., Tara J. Yosso, and Daniel G. Solórzano. 2007. "Racial Primes and Black Misandry on Historically White Campuses: Toward Critical Race Accountability in Educational Administration." Educational Administration Quarterly 43(5): 559-585.

Stanley, Christine A., ed. 2007. Faculty of Color: Teaching in Predominantly White Colleges and Universities. Bolton, MA: Anker.

Strauss, Anselm and Juliet M. Corbin. 1998. Basics of Qualitative Research: Grounded Theory Procedures and Techniques. Newbury Park, CA: Sage.

Sue, Derald W., 2004. "Whiteness and Ethnocentric Monoculturalism: Making the Invisible Visible." American Psychologist 59(8): 761-769.

Sue, Derald W., Christina M. Capodilupo, Gina C. Torino, Jennifer M. Bucceri, Aisha M. B. Holder, Kevin L. Nadal, and Marta Esquilin. 2007. "Racial Micro-aggressions in Everyday Life: Implications for Clinical Practice." The American Psychologist 62(4):271-286.

Sue, Derald W., Kevin L. Nadal, Christina M. Capodilupo, Annie I. Linn, Gina C. Torino, and David P. Rivera. 2008. "Racial Micro-aggressions against Black Americans: Implications for Counseling." Journal of Counseling \& Development 86(3):330-338.

Thompson, Chasity Q. 2008. “Recruitment, Retention, and Mentoring Faculty of Color: The Chronicle Continues." New Directions for Higher Education 143:47-54.

Trower, Cathy A. 2009. "Toward a Greater Understanding of the Tenure Track for Minorities." Change: The Magazine of Higher Learning 41(5):38-45.

Turner, Caroline S. V. and Samuel L. Myers Jr. 2000. Faculty of Color in Academe: Bittersweet Success. Boston, MA: Allyn \& Bacon.

Turner, Caroline S.V., Juan Carlos Gonzalez, and J Luke Wood. 2008. "Faculty of Color in Academe: What 20 years of Literature Tells Us." Journal of Diversity in Higher Education 1(3):139-168.

U.S. Department of Education. 2011. National Center for Education Statistics, Integrated Postsecondary Education Data System (IPEDS). Washington, D.C.: National Center for Education Statistics. U.S. Department of Education. 2015. "The Condition of Education 2015 (NCES 2015-144), Characteristics of Postsecondary Faculty." Washington, DC: National Center for Education Statistics.

University of California Hastings College of the Law (n.d.). Effective policies and programs for

This article is protected by copyright. All rights reserved 
retention and advancement of women in academia. Retrieved October 1, 2015 http://www.worklifelaw.org/pubs/worklife academia FINAL.pdf

Valdez, Zulema. 2015. "The Abandoned Promise of Civil Rights." Sociological Forum 30(1): 612-616.

Whittaker, Joseph A., Beronda L. Montgomery, and Veronica G. Martinez Acosta. 2015. "Retention of Underrepresented Minority Faculty: Strategic Initiatives for Institutional Value Proposition Based on Perspectives from a Range of Academic Institutions." The Journal of Undergraduate Neuroscience Education 13(3):A136-A145.

Williams, David R. and Selina A. Mohammed. 2009. "Discrimination and Racial Disparities in Health: Evidence and Needed Research." Journal of Behavioral Medicine 32(1):20.

Williams, David R. and Ruth Williams-Morris. 2000. "Racism and Mental Health: The African American Experience." Ethnicity \& Health 5:243-268.

Wingfield, Adia Harvey and Joe Feagin. 2012. "The Racial Dialectic: President Barack Obama and the White Racial Frame." Qualitative Sociology 35(2):143-162.

Wingfield, Adia Harvey. 2013. No more invisible man: Race and gender in men's work. Philadelphia, PA: Temple University Press.

Wingfield, Adia Harvey and Renée Alston. 2014. Maintaining Hierarchies in Predominantly White Organizations: A Theory of Racial Tasks. American Behavioral Scientist 58:274-287.

Zambrana, Ruth E., Claudia Dorrington and Sally Alonzo Bell. 1997. Mexican American Women in Higher Education: A Comparative Study. Race, Gender \& Class 4(2):127-149.

Zambrana, Ruth E., Rashawn Ray, Michelle Espino, Corinne Castro, Beth Douthirt Cohen, Jennifer Eliason. 2015. “Don't Leave Us Behind: The Importance of Mentoring for Underrepresented Minority Faculty." American Educational Research Journal 53(1):40-72.

Zanoni, Patrizia, Maddy Janssens, Yvonne Benschop, and Stella Nkomo. 2010. “Unpacking Diversity, Grasping Inequality: Rethinking Difference through Critical Perspectives." Organization 17(1):929. 


\begin{tabular}{|c|c|c|c|c|c|c|c|}
\hline \multicolumn{8}{|l|}{ Cognitive Appraisal } \\
\hline & \multirow[b]{2}{*}{$\begin{array}{l}\text { Total } \\
(\mathrm{N}=543)\end{array}$} & \multicolumn{2}{|c|}{ African American } & \multicolumn{2}{|c|}{ Mexican Origin } & \multicolumn{2}{|c|}{ Puerto Rican } \\
\hline - & & $\begin{array}{l}\text { Male } \\
n=126(\%)\end{array}$ & $\begin{array}{l}\text { Female } \\
n=207(\%)\end{array}$ & $\begin{array}{l}\text { Male } \\
n=51(\%)\end{array}$ & $\begin{array}{l}\text { Female } \\
n=83(\%)\end{array}$ & $\begin{array}{l}\text { Male } \\
n=36(\%)\end{array}$ & $\begin{array}{l}\text { Female } \\
n=40(\%)\end{array}$ \\
\hline \multicolumn{8}{|c|}{ Racial/Ethnic Discrimination by superior or colleague } \\
\hline Never $=1$ & $73(13 \%)$ & $21(17 \%)$ & $25(12 \%)$ & $11(22 \%)$ & $5(6 \%)$ & $6(17 \%)$ & $5(13 \%)$ \\
\hline Rarely $=2$ & $215(40 \%)$ & $48(38 \%)$ & $78(38 \%)$ & 30 (59\%) & $32(39 \%)$ & $16(44 \%)$ & $11(28 \%)$ \\
\hline Often/Always=3 & $238(44 \%)$ & $50(40 \%)$ & $99(48 \%)$ & $10(20 \%)$ & $43(52 \%)$ & $14(39 \%)$ & $22(55 \%)$ \\
\hline \multicolumn{8}{|c|}{ Gender Discrimination by superior or colleague } \\
\hline Never $=1$ & $172(32 \%)$ & 77 (61\%) & $36(17 \%)$ & $28(54.9)$ & $6(7.23)$ & $19(52.78)$ & $6(15.0)$ \\
\hline Rarely $=2$ & $192(35 \%)$ & $30(24 \%)$ & $85(41 \%)$ & $21(41 \%)$ & $33(40 \%)$ & $10(28 \%)$ & $13(33 \%)$ \\
\hline Often/Always=3 & $161(30 \%)$ & $12(10 \%)$ & $80(39 \%)$ & $2(4 \%)$ & $41(49 \%)$ & 7 (19\%) & $19(48 \%)$ \\
\hline \multicolumn{8}{|c|}{ Class Discrimination by superior or colleague } \\
\hline Never $=1$ & $180(33 \%)$ & $47(37 \%)$ & $65(31 \%)$ & $23(45 \%)$ & $19(23 \%)$ & $11(31 \%)$ & $15(38 \%)$ \\
\hline Rarely $=2$ & $212(39 \%)$ & $46(37 \%)$ & $89(43 \%)$ & $14(27 \%)$ & $40(48 \%)$ & $14(39 \%)$ & $9(23 \%)$ \\
\hline Often/Always=3 & $125(23 \%)$ & $26(21 \%)$ & $44(21 \%)$ & $13(25 \%)$ & $19(23 \%)$ & $10(28 \%)$ & $13(35 \%)$ \\
\hline \multicolumn{8}{|c|}{ Left out of Opportunities based on Gender } \\
\hline Never $=1$ & $236(43 \%)$ & $81(60 \%)$ & $55(27 \%)$ & $43(84 \%)$ & $21(25 \%)$ & $24(67 \%)$ & $12(30 \%)$ \\
\hline Rarely $=2$ & $165(30 \%)$ & $25(20 \%)$ & $78(38 \%)$ & $10(20 \%)$ & $31(37 \%)$ & $7(19 \%)$ & $14(35 \%)$ \\
\hline Often/Always=3 & $119(22 \%)$ & $13(10 \%)$ & $63(30 \%)$ & --- & $28(34 \%)$ & $3(8 \%)$ & $12(30 \%)$ \\
\hline \multicolumn{8}{|c|}{ Left out of Opportunities based on Race/Ethnicity } \\
\hline Never $=1$ & $140(26 \%)$ & $38(30 \%)$ & $39(19 \%)$ & $21(41 \%)$ & $21(25 \%)$ & $12(33 \%)$ & $9(23 \%)$ \\
\hline Rarely $=2$ & $192(35 \%)$ & $37(29 \%)$ & $72(35 \%)$ & $22(43 \%)$ & $34(41 \%)$ & $14(39 \%)$ & $13(33 \%)$ \\
\hline Often/Always=3 & $183(34 \%)$ & 42 (33\%) & $84(41 \%)$ & $8(16 \%)$ & $25(30 \%)$ & $9(25 \%)$ & 15 (38\%) \\
\hline \multicolumn{8}{|c|}{ Left out of Opportunities based on Class } \\
\hline Never $=1$ & $252(46 \%)$ & $70(56 \%)$ & $87(42 \%)$ & $29(57 \%)$ & $31(37 \%)$ & $17(47 \%)$ & $18(45 \%)$ \\
\hline Rarely $=2$ & $180(33 \%)$ & 31 (25\%) & $82(40 \%)$ & $13(25 \%)$ & $30(36 \%)$ & $12(33 \%)$ & $12(30 \%)$ \\
\hline Often/Always=3 & $81(15 \%)$ & $17(13 \%)$ & $25(12 \%)$ & $8(16 \%)$ & $18(22 \%)$ & $5(14 \%)$ & $8(20 \%)$ \\
\hline Mean (SD) & 11.45 & 10.77 & 12.27 & 9.87 & 12.83 & 10.56 & 12.65 \\
\hline
\end{tabular}

This article is protected by copyright. All rights reserved 


\begin{tabular}{|l|l|l|l|l|l|l|l|l|}
\hline $\begin{array}{l}\text { Discrimination } \\
\text { Scale }\end{array}$ & $(3.56)$ & $(3.59)$ & $(3.63)$ & $(2.66)$ & $(3.06)$ & $(3.49)$ & $(4.27)$ \\
\hline \multicolumn{2}{|l|}{ Impact of Discrimination } & $256(47 \%)$ & $50(40 \%)$ & $105(51 \%)$ & $20(39 \%)$ & $48(58 \%)$ & $15(42 \%)$ & $18(45 \%)$ \\
\hline $\begin{array}{l}\text { Extremely/Very } \\
\text { Upsetting=1 }\end{array}$ & $161(30 \%)$ & $32(25 \%)$ & $67(32 \%)$ & $13(25 \%)$ & $26(31 \%)$ & $9(25 \%)$ & $14(35 \%)$ \\
\hline $\begin{array}{l}\text { Somewhat/Mildly } \\
\text { Upsetting=2 }\end{array}$ & $85(16 \%)$ & $30(24 \%)$ & $22(11 \%)$ & $13(25 \%)$ & $4(4.8 \%)$ & $10(28 \%)$ & $6(18 \%)$ \\
\hline $\begin{array}{l}\text { Not Upsetting at } \\
\text { All=3 }\end{array}$ & & & & & \\
\hline
\end{tabular}
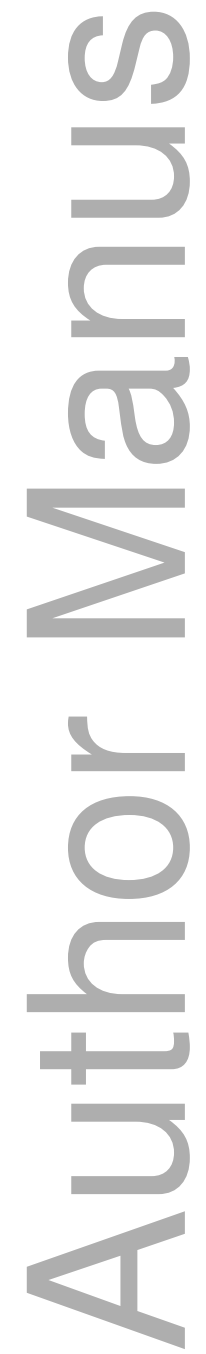

This article is protected by copyright. All rights reserved 